\title{
Letter to the editor: Vaccinating healthcare workers: evidence and ethics
}

H Kelly (heath.kelly@mh.org.au)

1. Australian National University, Canberra. Australia

Citation style for this article:

Kelly H. Letter to the editor: Vaccinating healthcare workers: evidence and ethics. Euro Surveill. 2015;20(2):pii=21006. Available online: http://www. eurosurveillance.org/ViewArticle.aspx?Articleld=21006

\section{To the editor:}

In a recent issue of Eurosurveillance, Betsch argued that vaccination of healthcare workers (HCWs) will prevent transmission of pathogens from HCWs to patients and that HCW vaccination should be encouraged by correcting skewed impressions of risk and by an appeal to altruistic or 'pro-social' motivation [1]. Using hepatitis $B$ and influenza vaccines as examples, Betsch noted there appeared to be less resistance to hepatitis $B$ than to influenza vaccination, quoting a study of German medical students showing $87 \%$ vaccination coverage against hepatitis B compared with $35 \%$ against influenza [2].

While there are a number of accepted reasons that $\mathrm{HCWs}$ refuse vaccination [3] part of the explanation for this observation may also be the different perception of these two vaccines.

In the early trials of hepatitis B vaccine targeting atrisk seronegative human immunodeficiency virus (HIV) infected men, hepatitis B vaccine provided $92 \%$ protection [4]. This level of protection has been repeatedly confirmed and population-based vaccination programmes in the past 20 years have reduced the burden of hepatitis $B$ in many previously highly endemic countries $[5,6]$.

Inactivated influenza vaccines are less effective than hepatitis B vaccines. Evidence from contemporary meta-analyses of randomised controlled trials suggest point estimates of efficacy of influenza vaccines of $59 \%$ [ 7 ] and $52 \%$ to $65 \%$, with the latter range depending on the degree of match between the circulating and vaccine strains [8]. These trials were performed in healthy adults, who would be generally representative of HCWs. A meta-analysis of observational case testnegative studies in older people - who are targeted for influenza vaccination in most countries with publicly funded programmes - suggested that inactivated influenza vaccines were of the order of $50 \%$ effective [9].

Annual vaccination is needed to provide immunity against influenza, but because the influenza vaccine is only partially effective, immunity will only be partial. Only three or four primary doses of hepatitis B vaccine are needed to confer probable lifelong immunity in most recipients [10].

Vaccinating HCW against hepatitis B will provide very good protection for both the HCW and subsequently the HCW's patients, with systems usually in place to identify the small proportion of people who fail to respond to vaccine. Unfortunately, we cannot reach the same conclusion about vaccinating HCW against influenza when the aim of vaccination is to protect patients from hospital-acquired influenza. Firstly, given that most HCWs can be considered as healthy working adults, a group for which the influenza vaccine has been shown to be only moderately effective, influenza vaccination does not guarantee immunity against influenza for the $\mathrm{HCW}[7,8]$. Secondly, HCWs are not the only source of influenza for hospitalised patients. In a review of 28 published studies of influenza outbreaks in hospitals, HCWs were assessed as the outbreak source in 10 (35\%) outbreaks, patients in six (22\%) outbreaks and friends and visitors in six (22\%) outbreaks. No source was identified for the remaining six (22\%) outbreaks [11]. Lastly, there are no good quality studies to suggest vaccinating HCWs against influenza protects patients in hospitals from laboratory-confirmed influenza. Existing evidence on protection of patients is derived from cluster randomised trials or observational studies in nursing homes and is based on non-specific outcomes, such as prevention of all-cause mortality [12]. Non-specific outcomes have been shown to produce biased estimates of direct influenza vaccine effectiveness in this patient group [13]. Such biases may well be amplified when considering indirect protection of older patients through incomplete HCW vaccination.

Despite these shortcomings, however, one can mount an ethical argument for vaccinating HCWs who care for patients, Firstly, with only occasional exceptions, inactivated influenza vaccines are safe. Secondly, influenza vaccines may protect HCWs, their families and patients from influenza. Thirdly, HCWs have a duty of care to protect their patients. The ethical argument is 
stronger when made in the context of a hospital respiratory infection prevention programme, which may also include respiratory precautions and appropriate sickness absence behaviour.

However, it may be more difficult to make an ethical argument for HCWs who do not have direct patient contact when vaccination would only be done to protect the HCW. In this case, encouraging or mandating vaccination may compromise the ethical principles of autonomy and bodily integrity. In this context, vaccination of $\mathrm{HCWs}$ is restricted to those with patient contact in the United Kingdom (UK) [14]. However, differential treatment of HCWs (with and without direct patient contact) can also introduce an ethical dilemma. Aristotle's principle of justice maintains that equals should be treated equally.

The evidence for vaccinating populations against hepatitis $B$ is strong and there are vaccination programmes in many endemic and non-endemic countries. On the other hand, while there is good evidence that influenza vaccines provide modest protection to recipients in most years, there is no good evidence that vaccinating HCWs in hospitals will protect their patients from influenza. It has been frequently argued that the ethical reasons for vaccinating HCWs against influenza to protect their patients outweigh the lack of evidence of benefit. Yet the ethical argument is not straightforward, with different arguments able to be advanced for HCWs with and without direct patient contact. Not all jurisdictions adopt the same approach to HCW influenza vaccination as the UK. It is hardly surprising then that the debate continues. What remains surprising is some of the ethical and evidential arguments used in the debate.

\section{Acknowledgements}

I thank Richard Pebody for valuable comments and advice.

Conflict of interest

None declared.

Authors' contributions

HK is the sole author and takes responsibility for all views expressed.

\section{References}

1. Betsch C. Overcoming healthcare workers vaccine refusal - competition between egoism and altruism. Euro Surveill. 2014;19(48):20979. http://dx.doi.org/10.2807/1560-7917. ES2014.19.48.20979 PMID:25496574

2. Wicker S, Rabenau HF, von Gierke L, François G, Hambach $R$, De Schryver A. Hepatitis B and influenza vaccines: important occupational vaccines differently perceived among medical students. Vaccine. 2013;31(44):5111-7. http://dx.doi. org/10.1016/j.vaccine.2013.08.070 PMID:24016807

3. Hollmeyer HG, Hayden F, Poland G, Buchholz U. Influenza vaccination of health care workers in hospitals--a review of studies on attitudes and predictors. Vaccine.
2009;27(30):3935-44. http://dx.doi.org/10.1016/j. vaccine.2009.03.056 PMID:19467744

4. Szmuness W, Stevens CE, Harley EJ, Zang EA, Oleszko WR, William DC, et al. Hepatitis B vaccine: demonstration of efficacy in a controlled clinical trial in a high-risk population in the United States. N Engl J Med. 1980;303(15):833-41. http:// dx.doi.org/10.1056/NEJM198010093031501 PMID:6997738

5. Park NH, Chung YH, Lee HS. Impacts of vaccination on hepatitis $B$ viral infections in Korea over a 25 -year period. Intervirology. 2010;53(1):20-8. http://dx.doi.org/10.1159/000252780 PMID:20068337

6. Yang SG, Wang B, Chen P, Yu CB, Deng M, Yao J, et al. Effectiveness of HBV vaccination in infants and prediction of HBV prevalence trend under new vaccination plan: findings of a large-scale investigation. PLoS ONE. 2012;7(10):e47808. http:// dx.doi.org/10.1371/journal.pone.0047808 PMID:23094094

7. Osterholm MT, Kelley NS, Sommer A, Belongia EA. Efficacy and effectiveness of influenza vaccines: a systematic review and meta-analysis. Lancet Infect Dis. 2012;12(1):36-44. http:// dx.doi.org/10.1016/S1473-3099(11)70295-X PMID:22032844

8. Tricco AC, Chit A, Soobiah C, Hallett D, Meier G, Chen MH, et al. Comparing influenza vaccine efficacy against mismatched and matched strains: a systematic review and meta-analysis. BMC Med. 2013;11(1):153. http://dx.doi.org/10.1186/1741-7015-11-153 PMID:23800265

9. Darvishian M, Bijlsma MJ, Hak E, van den Heuvel ER. Effectiveness of seasonal influenza vaccine in communitydwelling elderly people: a meta-analysis of testnegative design case-control studies. Lancet Infect Dis. 2014;14(12):1228-39. http://dx.doi.org/10.1016/S14733099(14)70960-0 PMID:25455990

10. Leuridan E, Van Damme P. Hepatitis B and the need for a booster dose. Clin Infect Dis. 2011;53(1):68-75. http://dx.doi. org/10.1093/cid/cir270 PMID:21653306

11. Voirin N, Barret B, Metzger M-H, Vanhems P. Hospitalacquired influenza: a synthesis using the Outbreak Reports and Intervention Studies of Nosocomial Infection (ORION) statement. J Hosp Infect. 2009;71(1):1-14. http://dx.doi. org/10.1016/j.jhin.2008.08.013 PMID:18952319

12. Ahmed F, Lindley MC, Allred N, Weinbaum CM, Grohskopf L. Effect of influenza vaccination of healthcare personnel on morbidity and mortality among patients: systematic review and grading of evidence. Clin Infect Dis. 2014;58(1):50-7. http:// dx.doi.org/10.1093/cid/cit580 PMID:24046301

13. Jackson LA, Nelson JC, Benson P, Neuzil KM, Reid RJ, Psaty BM, et al. Functional status is a confounder of the association of influenza vaccine and risk of all cause mortality in seniors. Int J Epidemiol. 2006;35(2):345-52. http://dx.doi.org/10.1093/ije/ dyi275 PMID:16368724

14. Public Health England (PHE). Healthcare worker vaccination: clinical evidence (updated August 2014). London:PHE. [Accessed 15 Dec 2014]. Available from: http://www. nhsemployers.org/ /media/Employers/Documents/ Campaigns/Flu\%2ofighter/Digital\%2oresources/Clinical\%20 evidence\%2021\%20August_1.pdf 